\title{
El dispositivo de la propaganda en las redes sociales de la campaña presidencial de El Salvador (2018-2019)
}

The propaganda dispositive through social media during the presidential campaign in El Salvador (2018-2019)

\section{Tatiana Orantes}

Universidad Centroamericana José Simeón Cañas, San Salvador, El Salvador tatianaorantesragmail.com

https://orcid.org/0000-0002-7686-9971

\section{Resumen}

El artículo analiza de forma cualitativa el despliegue de las prácticas discursivas y no discursivas, generadas y difundidas a través de redes sociales, mediante las cuales el dispositivo de la propaganda puede operar en el marco de una campaña política permitiendo la verificación de imaginarios sociales. Los elementos de campaña adquieren un orden y sentido cuando se articulan en discursos de verdad y prácticas de verificación. El propósito es determinar el campo conceptual en el que se daría esta vinculación entre propaganda, redes sociales, dispositivos de poder-saber e imaginarios sociales, así como describir sus características y principios de construcción comunes en la campaña presidencial de El Salvador, durante los meses de octubre de 2018 a febrero de 2019, en la que resultó electo el presidente Nayib Bukele.

Palabras clave: dispositivo de propaganda, campaña presidencial, redes sociales, imaginarios sociales, San Salvador.

\begin{abstract}
Based upon a qualitative approach, the article analyzes the deployment of discursive and nondiscursive practices, distributed over social media, through which the device of propaganda can operate within the framework of a political campaign, and would allow the verification of social imaginaries. The campaign elements acquire order and meaning when they are articulated on discourses of true and verification practices. The purpose is to determine the conceptual field in which the relations between the notion of propaganda, social media, powerknowledge dispositives and social imaginaries would occur, as well as to describe their characteristics and common construction principles at the core of the presidential campaign in El Salvador, during the months of October 2018 to February 2019, in which president Nayib Bukele was elected.
\end{abstract}

Keywords: propaganda, dispositive, campaign, social media, social imaginaries, San Salvador. 


\section{Introducción}

Después de la Firma de los Acuerdos de Paz en 1992, la democracia en El Salvador avanzó al ritmo de un sistema de partidos políticos de polos discursivos-ideológicos. En 2019, el país conoció al primer presidente, en las últimas tres décadas, que no llegó al órgano ejecutivo con el partido de derecha ARENA (Alianza Republicana Nacionalista de El Salvador), ni con el partido de izquierda FMLN (Frente Farabundo Martí para la Liberación Nacional). Cuando Bukele compitió para la presidencia a través de su alianza con el partido de derecha GANA (Gran Alianza por la Unidad Nacional) no presentó un proyecto partidario ideológico: en su lugar, concentró toda la campaña en su figura política y en el naciente partido "Nuevas Ideas", como antagonista de los partidos tradicionales.

Nayib Bukele se convirtió en una figura pública a partir de su papel como alcalde del municipio de Nuevo Cuscatlán y, después, como alcalde de la capital San Salvador, por el FMLN (partido que le expulsó de sus filas por un incidente de violencia de género, pero bajo la sospecha pública de discrepancias irremediables con la cúpula del partido). Antes de ingresar a la vida política, Bukele no terminó sus estudios en Ciencias Jurídicas y se dedicó al sector empresarial, siguiendo un legado familiar.

En El Salvador las campañas electorales se caracterizaban por su trabajo en el territorio y publicidad en medios de comunicación. La campaña de 2019 fue "la primera elección presidencial en la que las redes sociales se impusieron como el principal canal de comunicación política del movimiento que terminó obteniendo más votos" (Marroquín \& Girón, 2019, p. 12). También tuvieron un papel relevante las páginas de difusión de fake news y la proliferación de cuentas de trolls y bots. El trabajo territorial no estuvo ausente, pero sí fuera del foco mediático y mediatizado.

Para analizar este contexto, el artículo hace énfasis en las nociones de dispositivos de poder desarrolladas por Foucault $(1975,1977,1978,1979)$, Agamben (2011) y Deleuze (1986, 1995, 1999); el concepto de imaginarios sociales en Castoriadis (1987) y Taylor (2004); asimismo, se identificó la definición de propaganda en autores como Domenach (1968), Ellul (1973), Pratkanis \& Aronson
(1994), Pizarroso (1999), Eire \& Guervós (2000) y Taylor (2003), Bernays (2008), Tello (2017); y se abordaron investigaciones sobre el papel de las redes sociales en la comunicación política en autores/as como Carlini (2018), Cortés e Isaza (2017), Scolari (2012) y Toret (2013).

La metodología se basó en el estudio cualitativo de los materiales audiovisuales difundidos en las redes sociales del candidato durante el periodo de campaña. Para ello, se propuso la integración de diversas técnicas de recolección y análisis en un instrumento propio, conformado por categorías de la Teoría Fundamentada (Glaser \& Strauss, 1967), el Análisis del Discurso y el Análisis de Dispositivos (Jäger, 2001).

Los resultados permitieron entender cómo la propaganda operó en redes sociales como un dispositivo capaz de desplegar prácticas discursivas y no discursivas, alrededor de singularidades que se encontraban y distanciaban en diferentes momentos: (i) la homogeneización de los partidos políticos, (ii) la personalización de la historia, (iii) la gestión de probabilidades electorales y (iv) la modernización de la cotidianidad. Dicha red de prácticas y conocimientos permitiría la verificación de significaciones centrales, a saber: (i) el pueblo salvadoreño, (ii) la historia y el progreso y (iii) el gobierno democrático.

La importancia de este estudio radica en la consideración de la propaganda como dispositivo que juega un papel de correlación con otros procesos y dinámicas contemporáneas. Tiene un desarrollo en nuestros sistemas políticos híbridos latinoamericanos, entre la democracia y el autoritarismo, acompañados por la excepcionalidad como técnica de gobierno y un despliegue de relatos mediáticos sobre la amenaza permanente, ya sea del narcotráfico, las pandillas, la migración, el terrorismo y, más recientemente, la pandemia del Covid-19.

Otro de los fenómenos político-comunicacionales correlativos a esta temática es el populismo, donde es posible identificar una nebulosa de características: la moralización del conflicto político, la exclusión del diálogo democrático, los rasgos autoritarios en el discurso y la práctica para perpetuarse en el poder formal, los liderazgos personalistas y patriarcales, las figuras políticas outsiders del orden de partidos y de las instituciones democráticas, el reforzamiento simbólico y/o real de las fuerzas 
militares, la formulación de soluciones individuales a los problemas actuales y los discursos transversales anticorrupción y de progreso económico (Freidenberg, 2012). Se trata de un fenómeno cuyo sello reciente se relaciona con la posverdad y la desinformación en redes de información y comunicación, prácticas donde priman la velocidad y la cercanía facilitadas por la tecnología, con importantes rendimientos políticos y económicos.

\section{Marco teórico}

\subsection{Conjunciones: comunicación política y dispositivo propagandístico}

Una de las expresiones más conocidas de la comunicación política es la propaganda, en sus variantes, formatos y protagonistas. La propaganda en tanto uno de sus objetos de estudio deberá pensarse, además, desde un enfoque interdisciplinar y en una convergencia de medios con carácter interactivo entre individuos y lenguajes, especialmente en plataformas digitales. Para autores como Toret (2013), esta convergencia puede dar lugar a la capacidad de acción colectiva en la red, definida bajo el concepto de tecnopolítica, cuando se hace un uso táctico y estratégico de las herramientas digitales y de las identidades colectivas online para la organización, comunicación y acción colectiva.

Las redes sociales han adquirido relevancia para la comunicación política, por sus características de segmentación, personalización y medición. Sus dinámicas se asocian tanto a ser catalizadoras de los movimientos sociales, como a ser técnicas de desinformación, ahora en entornos digitales y bajo la categoría de posverdad (Carlini, 2018, p. 2).

La noción de propaganda como técnica de persuasión masiva no es algo propio del entorno digital, sino que se sustenta en teorías de los medios de comunicación desde inicios del siglo XX. Sus definiciones suelen ser divididas en tres conjuntos: concepciones que la asocian a la educación, el progreso y la democracia (Bernays, 2008; Ellul, 1973; Pratkanis \& Aronson, 1994); nociones que la comprenden como técnica de manipulación psicológica (Doob, 1950; Pizarroso, 1999; Pratkanis \&
Aronson, 1994), y nociones descriptivas referidas a la difusión de ideas, por cualquier grupo, estatal o no (Domenach, 1968; Sierra, s.f; Taylor, 2003; Ellul, 1973). En su lugar, la definimos a partir de la categoría dispositivo, como una red de prácticas, tecnologías, mecanismos, racionalidades y focos de poder, que no divide sino condensa las pugnas entre lo racional y lo emocional, lo público y lo privado, la realidad y sus representaciones.

\subsection{Entender la propaganda desde la noción de dispositivo}

Entre los dispositivos que convergen en la modernidad se encontraría la propaganda. Al igual que con la comunicación política, apostamos por una relación de conjunción entre propaganda y dispositivos, con base en los planteamientos de Foucault (1977, 1978, 1979), Agamben (2011) y Deleuze $(1986,1999)$. Aunque estos autores no se ocupan de estudiar el fenómeno de la propaganda, sí proporcionan una red de análisis, que relacionamos con el campo de la comunicación política. Llamamos a esta conjunción dispositivo propagandístico. Se trata de ver en la propaganda un dispositivo productivo, que relaciona prácticas de saber-poder, con diversas y fragmentarias formas de articularse, en relación con otros dispositivos contemporáneos como las redes sociales y en complementariedad con instrumentos más tradicionales, como la legislación y los procedimientos electorales. Entendemos el concepto de dispositivo como:

Un conjunto decididamente heterogéneo, que comprende discursos, instituciones, instalaciones arquitectónicas, decisiones reglamentarias, leyes, medidas administrativas, enunciados científicos, proposiciones filosóficas, morales, filantrópicas; en resumen: los elementos del dispositivo pertenecen tanto a lo dicho como a lo no dicho. El dispositivo es la red que puede establecerse entre estos elementos (Foucault, 1991, p. 128).

El dispositivo propagandístico sería (i) un conjunto heterogéneo de elementos, algunos de los cuales pueden encontrarse en otros dispositivos de gobierno, (ii) los elementos que lo unen pueden encontrarse también en diferentes formaciones históricas, a las que condicionan y en las que son 
condicionados, (iii) la propaganda sería algo más que los discursos difundidos mediáticamente, apela a prácticas no discursivas y acontecimientos singulares.

En un segundo nivel, siguiendo a Foucault (1991), la constitución del dispositivo es lugar de sobredeterminación funcional y relleno estratégico, que conformarían la matriz y racionalidad del dispositivo. Su potencia estratégica respondería a una "urgencia". En el caso de El Salvador, esta urgencia estratégica ha respondido a los niveles críticos de insostenibilidad de la vida y, más recientemente, a su agudización por la pandemia por Covid-19.

Tello (2017) plantea que la racionalidad política de la época, la matriz estratégica de los dispositivos modernos sería la gubernamentalidad liberal, conformada por dos elementos correlativos: el mercado y la opinión. Dicha racionalidad actuaría mediante la gestión de la vida, por una parte, y el control de la opinión del público a través de la propaganda, por otra.

Foucault (1977) remarca que estas estrategias de poder encuentran sus condiciones de ejercicio en las micro-relaciones de poder y no en los aparatos de Estado y sus instituciones. Por ello, no las considera como relaciones impuestas de arriba abajo, pues habrían también "movimientos de retorno" (p. 30). Deleuze (2014) dirá que las instituciones son "formas de integración de microrelaciones de poder" (p. 119). Para nuestras consideraciones, los medios de comunicación y los grupos de poder son las instancias molares por excelencia, mientras las dinámicas de las redes sociales son más parecidas a las de los dispositivos moleculares de poder.

Para Scolari (2012), las narrativas transmedia abarcan diferentes medios y lenguajes y deben responder a algunos principios que Scolari retoma de Moloney (2012): la expansión y serialidad pueden ser percibidas a través de prácticas virales en redes sociales (\#devuelvanlorobadochallenge); la continuidad y multiplicidad, en los diferentes lenguajes, medios y plataformas donde se comparten los contenidos; la inmersión y extraibilidad se refleja en el contenido generado por cuentas afines al partido de maneras creativas; la red hipertextual y las subjetividades múltiples se refieren a las miradas y perspectivas que se generarán en y a partir del contenido político.

A la descripción de las sociedades de control hace falta preguntarle sobre el tipo de experiencia social que los individuos tienen con los dispositivos y en ellos. Agamben (2011) considera que (i) en la fase del desarrollo capitalista hay una acumulación y proliferación de dispositivos, donde (ii) se establecen dos clases: los seres vivos y los dispositivos y, en la relación cuerpo a cuerpo de estas clases, una tercera: los sujetos (iii), donde todo dispositivo implica un proceso de subjetivación, sin el cual no podría funcionar como dispositivo de gobierno.

En los dispositivos tecnológicos y redes sociales existen ciertos ofrecimientos o propiedades que surgen a partir de la relación entre el objeto y la persona, es decir, cuando las tecnologías permiten ciertas acciones sociales, como la generación y difusión de fake news, teorías conspirativas, cadenas de desinformación y la configuración de burbujas de opinión (Cortés \& Isaza, 2017).

Los principios de esta microfísica del poder, por la cual operan los dispositivos, son aplicables al caso de estudio: no existe una esencia o atributo sobre la propaganda ni podemos hablar de forma determinante sobre sus efectos en la sociedad. El poder ejercido no se trataría de una propiedad conquistada ni se encontraría localizado únicamente en el Estado y los partidos políticos, sino en un juego de relaciones de fuerzas y saberes. Es decir, no estaría por encima de las demás relaciones sociales, sino vinculándolas. Su poder no actuaría por medio de violencia estatal e ideología mediatizada, sino en la producción positiva de significaciones sociales en relación al dispositivo social media, que facilitaría la justificación de prácticas opresivas y antidemocráticas.

En El Salvador este mecanismo operó durante el 9F, cuando en su primer mes de gobierno, el presidente ocupó la silla legislativa rodeado de un fuerte operativo militar que se repitió durante el 1 de mayo de 2021, cuando la nueva Asamblea Legislativa, conformada en su mayoría por diputados y diputadas del partido Nuevas Ideas, aprobó la destitución de las y los magistrados de la Sala de lo Constitucional y del Fiscal General de la República. 


\subsection{Los imaginarios sociales de la propaganda}

Las prácticas del dispositivo se investirían de sentido cuando son sostenidas por significaciones imaginarias y requieren de una capacidad imaginante que les dé sentido, materializándolas en valoraciones, afectos, jerarquías, normas y desviaciones vinculadas colectivamente en la memoria histórica y personal de los sujetos.

De acuerdo a Castoriadis (2013), en lo social-histórico se crearían las condiciones de posibilidad de los dispositivos, vinculadas a las demás significaciones imaginarias de la sociedad (mercancías, patria, sexualidad, ritos), alrededor de las cuales se configuran las relaciones creadas y posicionadas. Es por ello que, en tanto dispositivo, la propaganda de la campaña presidencial verifica estas significaciones sociales, dando cuenta de lo considerado (no)valioso, (no)posible y (no)necesario en la sociedad salvadoreña y encuentra en las redes sociales un dispositivo importante para complementarse y potenciarse, con rendimientos políticos electorales importantes.

Finalmente, es importante establecer orientaciones metodológicas respecto a los imaginarios sociales teorizados por Castoriadis (2013) y Taylor (2004). Estos solo pueden ser reconstruidos a partir de sus manifestaciones, donde aparecen como fundamento de posibilidad y unidad. La significación imaginaria puede ser una imagen, pero en tanto que significación imaginaria, más bien es su condición de posibilidad. Las significaciones imaginarias no existen, propiamente; sólo pueden ser captadas de manera derivada y oblicua (Castoriadis, 2013).

\section{Marco metodológico}

Bajo un enfoque cualitativo, se analizó una serie de piezas audiovisuales que circularon durante la campaña electoral, entre octubre de 2018 y febrero de 2019. Entre las piezas audiovisuales se encuentran narrativas de diversa índole, como historias de vida, discursos, cortos documentales, entrevistas, notas periodísticas, y coberturas de eventos. Asi- mismo, se acotó la selección a aquellos materiales difundidos por redes sociales y no otros espacios, debido a que este canal ha sido el más utilizado y un eje de la campaña, con énfasis en un público objetivo joven y con acceso a Internet.

Las piezas audiovisuales se escogieron por su:
a) Formato audiovisual
b) Contenido político electoral
c) Difundidas en el periodo de campaña
d) Difundidas en las cuentas oficiales del candidato
e) Producidas por movimientos ciudadanos y retomadas en las cuentas oficiales del candidato.

A partir de estos criterios se recopilaron 56 videos de un total de 68 , con una duración entre los 20 segundos y los 30 minutos. Todos ellos fueron difundidos en Facebook, Youtube, Instagram y Twitter de Nayib Bukele y las cuentas Botón Celeste.

Para contrastar los planteamientos del marco teórico, se propuso acudir a los siguientes pasos de la Teoría Fundamentada de Glaser \& Strauss (1967):
a) Establecimiento de un corpus propagandístico
b) Operativización de conceptos del marco teórico
c) Extracción de categorías de sentido del corpus que permitan ser relacionadas con los conceptos teóricos operativizados
d) Establecimiento de relaciones entre los modos concretos de acción del dispositivo propagandístico y la verificación de imaginarios sociales en el caso concreto.

En relación con el Análisis de Discursos y Análisis de Dispositivos, los aspectos teóricos y metodológicos propuestos por Jäger (2001) son útiles pues resuelven la relación entre dos dimensiones relevantes: prácticas (no)discursivas y dispositivos. Jäger (2001) sintetiza que las dificultades en la determinación del dispositivo guardan relación con la incapacidad de establecer la mediación entre el discurso (lo que se dice y lo que se ha dicho), las prácticas no discursivas (actividades) y las manifestaciones (productos y objetos). Considera, además, que estas manifestaciones son materializaciones y actividades del saber (discursos) y que las prácticas 
no discursivas son la actividad/puesta en práctica del saber. Aunque no se trata de un análisis semiótico, en este método de análisis la visualidad (lo que se ve y sus condiciones de posibilidad) así como su dimensión verbal (lo que se dice y sus condiciones de posibilidad), están impregnadas de conocimiento $\mathrm{y}$ van precedidas de éste, como manifestaciones y materializaciones de las prácticas discursivas y no discursivas. Por ello, el instrumento de análisis incluye un apartado descriptivo-argumentativo que contempla ambas dimensiones.

Lo que intentamos desentrañar en las piezas audiovisuales, como un todo, son diferentes niveles: (i) nivel descriptivo-argumentativo, (ii) nivel de significaciones imaginarias, y (iii) nivel de las dimensiones del dispositivo. Las matrices utilizadas fueron:
A) Matriz de recolección de información y análisis (Tabla 1) conformada por categorías generales (nivel descriptivo, estructural y semántico-retórico), ancladas a las características del material audiovisual y las redes sociales; categorías del nivel pragmático de las narrativas, relacionadas al contexto de producción/formación discursiva; categorías que responden a los procesos de institución de sentido de los imaginarios sociales, y categorías de los dispositivos y sus dimensiones.

B) Matriz operativa (Tabla 2) con la que se relacionan los elementos observados, una vez reducida la información a partir de las categorías. El instrumento permitió la observación, comparación, relación y contraste de las unidades de sentido obtenidas.

Tabla 1: Matriz de recolección de información y análisis

Nivel descriptivo-argumentativo

\begin{tabular}{|c|c|c|c|c|c|c|}
\hline Título & & & & & \multicolumn{2}{|c|}{ Imagen de referencia } \\
\hline \multicolumn{7}{|l|}{ Temas } \\
\hline \multicolumn{7}{|l|}{ Redes sociales } \\
\hline \multicolumn{7}{|l|}{ Forma narrativa } \\
\hline \multicolumn{7}{|l|}{ Descripción } \\
\hline & \multicolumn{6}{|c|}{ Nivel de producción de sentido } \\
\hline & \multicolumn{3}{|c|}{ Significaciones } & \multicolumn{3}{|c|}{ Valoración } \\
\hline \multicolumn{7}{|l|}{ Significación 1} \\
\hline \multicolumn{7}{|l|}{ Significación n } \\
\hline & \multicolumn{6}{|c|}{ Nivel de los dispositivos } \\
\hline $\begin{array}{l}\text { Focos discursivos/ } \\
\text { no discursivos }\end{array}$ & Umbral (es) & $\begin{array}{l}\text { Escenas/ } \\
\text { lugares de } \\
\text { visibilidad }\end{array}$ & $\begin{array}{l}\text { Materias } \\
\text { formadas }\end{array}$ & $\begin{array}{l}\text { Palabras/ } \\
\text { frases/actos } \\
\text { discursivos }\end{array}$ & $\begin{array}{l}\text { Funciones } \\
\text { formalizadas }\end{array}$ & Acontecimientos \\
\hline \multicolumn{7}{|l|}{ Singularidad 1} \\
\hline \multicolumn{7}{|l|}{ Singularidad 2} \\
\hline Observaciones & & & & & & \\
\hline
\end{tabular}


Tabla 2: Matriz operativa

\begin{tabular}{|c|c|c|c|c|c|c|}
\hline Concepto & Definición & Dimensión & Indicador & Ítem & Definición & Preguntas \\
\hline \multirow[t]{3}{*}{$\begin{array}{l}\text { Imaginarios } \\
\text { sociales }\end{array}$} & \multirow[t]{3}{*}{ Taylor (2004) } & \multirow[t]{3}{*}{$\begin{array}{l}\text { Institución } \\
\text { social del } \\
\text { sentido }\end{array}$} & \multirow[t]{3}{*}{$\begin{array}{l}\text { Materializaciones } \\
\text { colectivamente } \\
\text { disponibles }\end{array}$} & $\begin{array}{l}\text { Imaginarios } \\
\text { centrales }\end{array}$ & $\begin{array}{l}\text { Castoriadis (2013, } \\
\text { p. 553-559) }\end{array}$ & $\begin{array}{l}\text { ¿Cuáles serían los } \\
\text { principios de orden } \\
\text { centrales a los que } \\
\text { se refiere el spot? }\end{array}$ \\
\hline & & & & $\begin{array}{l}\text { Significacio- } \\
\text { nes sociales }\end{array}$ & $\begin{array}{l}\text { Castoriadis } \\
(2013, \text { p. 552) }\end{array}$ & $\begin{array}{l}\text { ¿Sobre qué ideas } \\
\text { significativas } \\
\text { informa el spot? }\end{array}$ \\
\hline & & & & Valoración & $\begin{array}{l}\text { Castoriadis } \\
(2013, \text { p. 240) }\end{array}$ & $\begin{array}{c}\text { ¿Cuáles son los afectos } \\
\text { que se implican } \\
\text { sobre el spot? ¿Qué } \\
\text { valoración se les da a } \\
\text { estas significaciones? } \\
\text { ¿Se establece algún } \\
\text { principio de orden o } \\
\text { jerarquía? ¿se prevé } \\
\text { alguna falta/desviación? }\end{array}$ \\
\hline \multirow[t]{8}{*}{$\begin{array}{c}\text { Dispositivo } \\
\text { propagandístico }\end{array}$} & \multirow[t]{2}{*}{$\begin{array}{c}\text { Foucault } \\
\text { (1991, p. 128) }\end{array}$} & \multirow[t]{2}{*}{$\begin{array}{l}\text { Relación de } \\
\text { elementos } \\
\text { heterogéneos }\end{array}$} & \multirow[t]{4}{*}{$\begin{array}{c}\text { Prácticas } \\
\text { discursivas y } \\
\text { no discursivas }\end{array}$} & $\begin{array}{l}\text { Focos de } \\
\text { poder/re- } \\
\text { sistencia }\end{array}$ & $\begin{array}{c}\text { Deleuze (2014, } \\
\text { p. } 394) \\
\text { Deleuze (2014, } \\
\text { p. 24) } \\
\text { Deleuze (2014 }\end{array}$ & $\begin{array}{l}\text { ¿Cuáles son las } \\
\text { singularidades alrededor } \\
\text { de/sobre las cuales se } \\
\text { pronuncian discursos? }\end{array}$ \\
\hline & & & & Umbrales & $\begin{array}{l}\text { Jäger (2001, } \\
\text { p. 82) }\end{array}$ & $\begin{array}{c}\text { ¿Cuáles son los campos } \\
\text { o esferas sociales desde } \\
\text { los que se habla? }\end{array}$ \\
\hline & $\begin{array}{c}\text { Foucault } \\
\text { (1991, p. 128) }\end{array}$ & $\begin{array}{l}\text { Dimensión es- } \\
\text { tratégica y de } \\
\text { contingencia }\end{array}$ & & $\begin{array}{l}\text { Contexto de } \\
\text { producción }\end{array}$ & Jäger, 2001, p. 82) & $\begin{array}{c}\text { ¿Cuál es el contexto } \\
\text { general al que } \\
\text { hace alusión? }\end{array}$ \\
\hline & Tello (2007) & $\begin{array}{l}\text { Raciona- } \\
\text { lidades de } \\
\text { gobierno }\end{array}$ & & $\begin{array}{l}\text { Aconteci- } \\
\text { mientos }\end{array}$ & Jäger, 2001, p. 82) & $\begin{array}{c}\text { ¿Qué acontecimientos } \\
\text { discursivos se relacionan } \\
\text { con los umbrales/ } \\
\text { planos identificados? }\end{array}$ \\
\hline & \multirow[t]{4}{*}{ Deleuze (1995) } & \multirow[t]{4}{*}{$\begin{array}{l}\text { Operaciones } \\
\text { de consti- } \\
\text { tución del } \\
\text { dispositivo }\end{array}$} & \multirow[t]{4}{*}{$\begin{array}{c}\text { Prácticas } \\
\text { discursivas y } \\
\text { no discursivas }\end{array}$} & $\begin{array}{l}\text { Escenas/co- } \\
\text { sas (régimen } \\
\text { de visibilidad) }\end{array}$ & $\begin{array}{l}\text { (Deleuze, } \\
\text { 2013, p. 87) } \\
\text { Deleuze, } \\
\text { 2013, p. 42) }\end{array}$ & $\begin{array}{l}\text { ¿Se mencionan } \\
\text { lugares desde los } \\
\text { cuales se observa } \\
\text { y/o son observados } \\
\text { los sujetos/cosas? }\end{array}$ \\
\hline & & & & $\begin{array}{l}\text { Materias } \\
\text { formadas del } \\
\text { proceso de } \\
\text { (subjetivación) }\end{array}$ & $\begin{array}{c}\text { (Deleuze, } \\
\text { 2014, p. 75). } \\
\text { Agamben (2011) }\end{array}$ & $\begin{array}{l}\text { ¿A qué sujetos/materias } \\
\text { formadas se refiere } \\
\text { el spot? ¿Qué sujetos } \\
\text { son mencionados, } \\
\text { presentados o adquieren } \\
\text { notoriedad en el spot? }\end{array}$ \\
\hline & & & & $\begin{array}{l}\text { Palabras/ } \\
\text { frases/actos } \\
\text { discursivos } \\
\text { (régimen de } \\
\text { enunciados) }\end{array}$ & $\begin{array}{l}\text { Deleuze (2013, } \\
\text { pp. 68-69) }\end{array}$ & $\begin{array}{l}\text { ¿Qué palabras, frases, } \\
\text { proposiciones o actos de } \\
\text { habla son regulares en el } \\
\text { spot? ¿Sobre qué objetos } \\
\text { se pronuncian discursos? }\end{array}$ \\
\hline & & & & $\begin{array}{l}\text { Funciones } \\
\text { formalizadas }\end{array}$ & $\begin{array}{l}\text { Deleuze (2014, } \\
\text { p. 150) } \\
\text { Deleuze (2014, } \\
\text { p. 78) }\end{array}$ & $\begin{array}{c}\text { ¿Qué acciones/funciones } \\
\text { se implican a las } \\
\text { materias formadas/ } \\
\text { sujetos identificados? }\end{array}$ \\
\hline
\end{tabular}

\section{Resultados}

A nivel descriptivo, la campaña electoral de Nayib Bukele presentó coherencia gráfica y una planificación identificable. Los formatos narrativos utilizados se dividieron en cinco conjuntos: (i) discursos por Facebook Live ( 5 videos); (ii) cobertura noticiosa (6 videos); (iii) animación (4 videos); (iv) spots temáticos (13 videos); (v) Cobertura de eventos de cam- paña (15 videos); (vi). Historias de vida (4 videos), y (vii) Otros (9 videos).

Los formatos audiovisuales que comprenden esta campaña electoral y el uso privilegiado de las redes sociales refieren a encadenamientos de sentido. Cada una de las piezas requiere de las demás para constituirse como una red hipertextual con múltiples referencias entre sí, aunque en su individualidad están cargadas de significantes. 


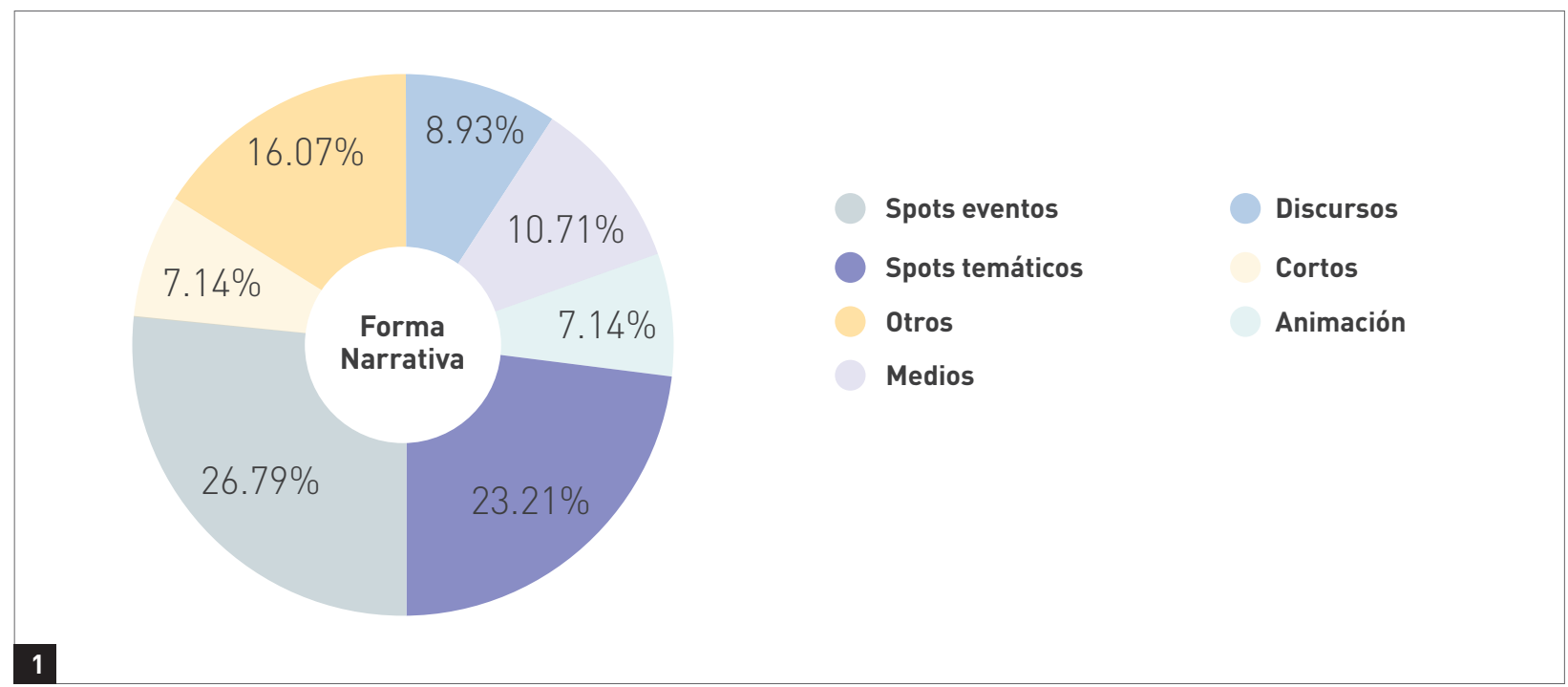

Imagen 1: Forma narrativa

Fuente: Elaboración propia.

\subsection{Nivel de análisis de imaginarios sociales}

Los imaginarios centrales que organizan la campaña en redes sociales son tres: (i) el pueblo, (ii) la historia y el progreso, y (iii) la democracia o el gobierno de los muchos. Sobre estas significaciones se inscriben las demás, que adquieren sentido sólo en y a través de su órbita imaginaria. A partir de estos imaginarios, se valoran a los candidatos/ as y a sus votantes, además de jerarquizar el conjunto de problemas/necesidades de la población salvadoreña.

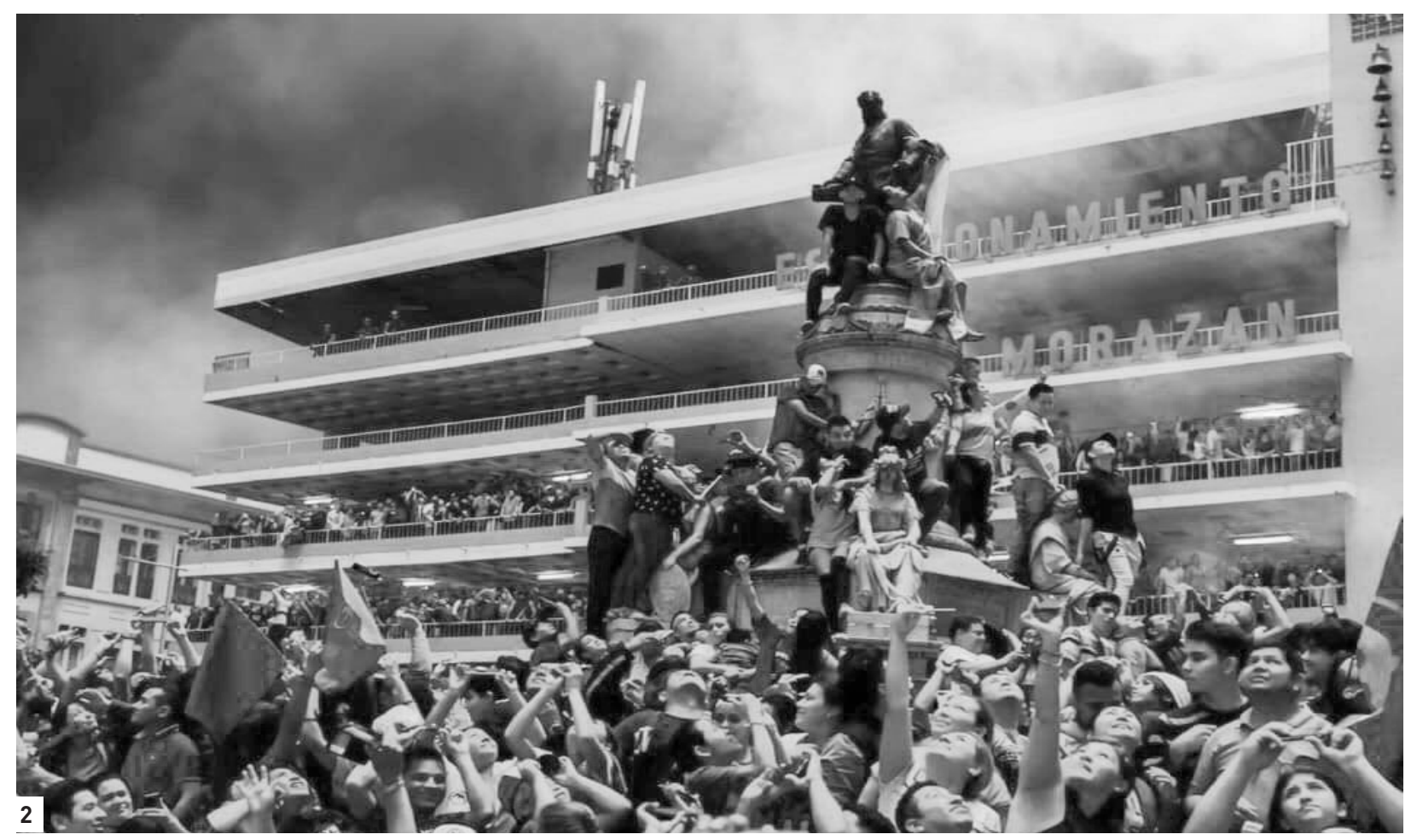

Imagen 2: Hace exactamente un año, estábamos haciendo historia (Bukele, 10 de febrero de 2019). 


\subsubsection{El pueblo salvadoreño}

“Nuevas Ideas es el pueblo salvadoreño unido con un solo objetivo: cambiar a nuestro país de una vez por todas. Sacar a los mismos de siempre del poder e iniciar una nueva era, un futuro de verdad para nuestros niños, para nuestros adultos mayores". El camino que recorrimos (Bukele, 30 de enero de 2019).

En una concepción de realidad en la que no se acepta la disonancia, Nayib Bukele es Nuevas Ideas y “Nuevas Ideas es el pueblo salvadoreño". La signficación pueblo es un elemento unificador, en tanto no son guiados por un proyecto político ideológico, sino por un sentimiento de indignación y malestar que se concreta en sus historias individuales de luto, dolor, desigualdad e injusticia. La historia es el individuo:

“Todos ustedes tienen a alguien a la par que pueden convencer, un familiar, un colega, un compañero de universidad, un vecino, un amigo, una hija, una madre, un abuelo. Alguien que pudiera estar todavía anclado en el pasado" Inicio de campaña presidencial (Bukele, 3 de octubre de 2018).

El otro es un individuo que se diferencia por su resistencia al cambio: algo impensable en una sociedad donde los sujetos modernos experimentamos diferentes lógicas de aceleración social, tecnológica y de la vida cotidiana, de acuerdo a Rosa (2013). Los otros testimonian la marginalidad de la que deseamos deshacernos, que se expresa como la experiencia de estar, actuar y sufrir en la desigualdad. Esta otra marginalidad es confirmada por las encuestas de opinión, en la ratificación del apoyo mayoritario conseguido por el candidato en una democracia de los muchos, suficiente razón para identificar a esta minoría por el dispositivo propagandístico.

Uno de los principios de la campaña presidencial fue la crítica a las élites partidarias y la visibilización del candidato como representante legítimo del pueblo: un pueblo nominado contra el bipartidismo. La paradoja es evidente: mientras más progresa la crítica hacia el sistema de partidos establecido, menos abiertos podrían encontrarse ante la revisión del mismo movimiento. Nuevas Ideas aboga por el fin de la exclusión social mediante la exclusión moral, a partir de la categoría pueblo instituida e instituyente del movimiento que se autodenomina popular.

\subsubsection{La historia y el progreso}

Las y los salvadoreños hacen historia. Esta fue la principal promesa de campaña, una que no se concreta sólo en proyectos u obras; más bien se aloja en el imaginario de la historia y el progreso de una sociedad. La jornada electoral, como lugar de decisión individual y a la vez colectiva, es donde cada una de las personas, pese al sentimiento de indignación con los personajes políticos que representan lo negativo del pasado, haría una reivindicación de sus aspiraciones personales y del futuro político del país.

En los spots electorales, la historia del país es contada como la historia de cada persona que se ha sentido excluida del progreso. Al pueblo salvadoreño lo une un pasado turbulento de dictaduras, masacres y corrupción; por tanto, se espera que su destino sea el progreso. Las elecciones serían una puerta a la modernidad que ha sido negada durante años.

En este escenario es coherente hablar de un imaginario social en el cual el futuro no se espera ni se proyecta, sino se actualiza en el presente a través del voto. A su vez, entre el pasado y el presente sólo se plantea la superación o un devenir progresivo. Por una parte, el pasado es representado de forma reiterativa por los expresidentes del país, como figuras de los partidos políticos cuyas administraciones podemos verificar en el presente. El pasado es exhumado con la esperanza de ser dejado atrás por la posibilidad del progreso.

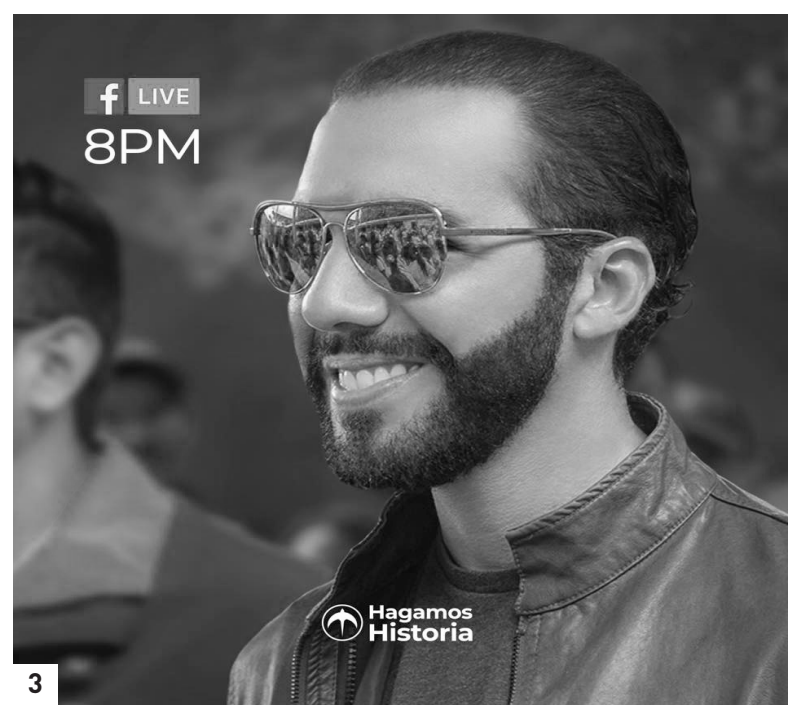

Imagen 3: Nos vemos aquí, a las 8 pm por Facebook Live (Bukele, 16 de diciembre de 2018). Fuente: Facebook 
Finalmente, según Lipovetsky \& Sébastien (2004) en la era hipermoderna no se ha destruido la fuerza del futuro; lo que ocurre es que ya no es únicamente un futuro ideológico-político, sino que se sustenta en la dinámica técnica y científica. De esta manera, el progreso de las ciudades y el programa de Nuevas Ideas se constituye menos en la glorificación de fines o ideales que en el culto al alcance de logros estadísticos: "una obra por día”, “millones de dólares invertidos", "miles de personas inscritas".

\subsubsection{El gobierno democrático}

En la propaganda de Nuevas Ideas la administración pública puede ser comprendida como una cuestión de escalas o de administración religiosa, que se resume claramente en uno de los spots: "El que es fiel en lo muy poco es fiel también en lo mucho". Los logros alcanzados a nivel municipal parecieran incorporarse, así, en una plataforma multinivel, capaz de expandirlos hasta hacerlos calzar con el territorio nacional.

De esta relación con la democracia se destaca también la percepción de la meritocracia como antónimo de corrupción. La meritocracia coincide con la narrativa del camino del héroe en la democracia y de la historización de las trayectorias individuales: una lucha cotidiana basada en los méritos y capacidades de quienes son considerados mejores o más esforzados. El partido que más se ha esforzado por existir, y luego por competir en la campaña electoral, ha sido Nuevas Ideas. La problemática se encontraría además en el saber sobre el que se distingue del resto de la población a las y los mejores y esforzados.

La victoria democrática de Nuevas Ideas implica actuar en el sistema partidario y democrático, pero también contra él. En los imaginarios relacionados a Nuevas Ideas la salvación del cuerpo del país se consumará con el sacrificio ritual de la otredad y la urna de votación sería su sentencia. En el día del juicio contra los representantes de las injusticias históricas, se desestabilizaría la balanza hacia la promesa de renovación y no más entre polos ideológicos de izquierda y de derecha, al menos discursivamente. Aun cuando esto mismo responda a la inteligibilidad de una ideología específica de un orden violento, autoritario y patriarcal.

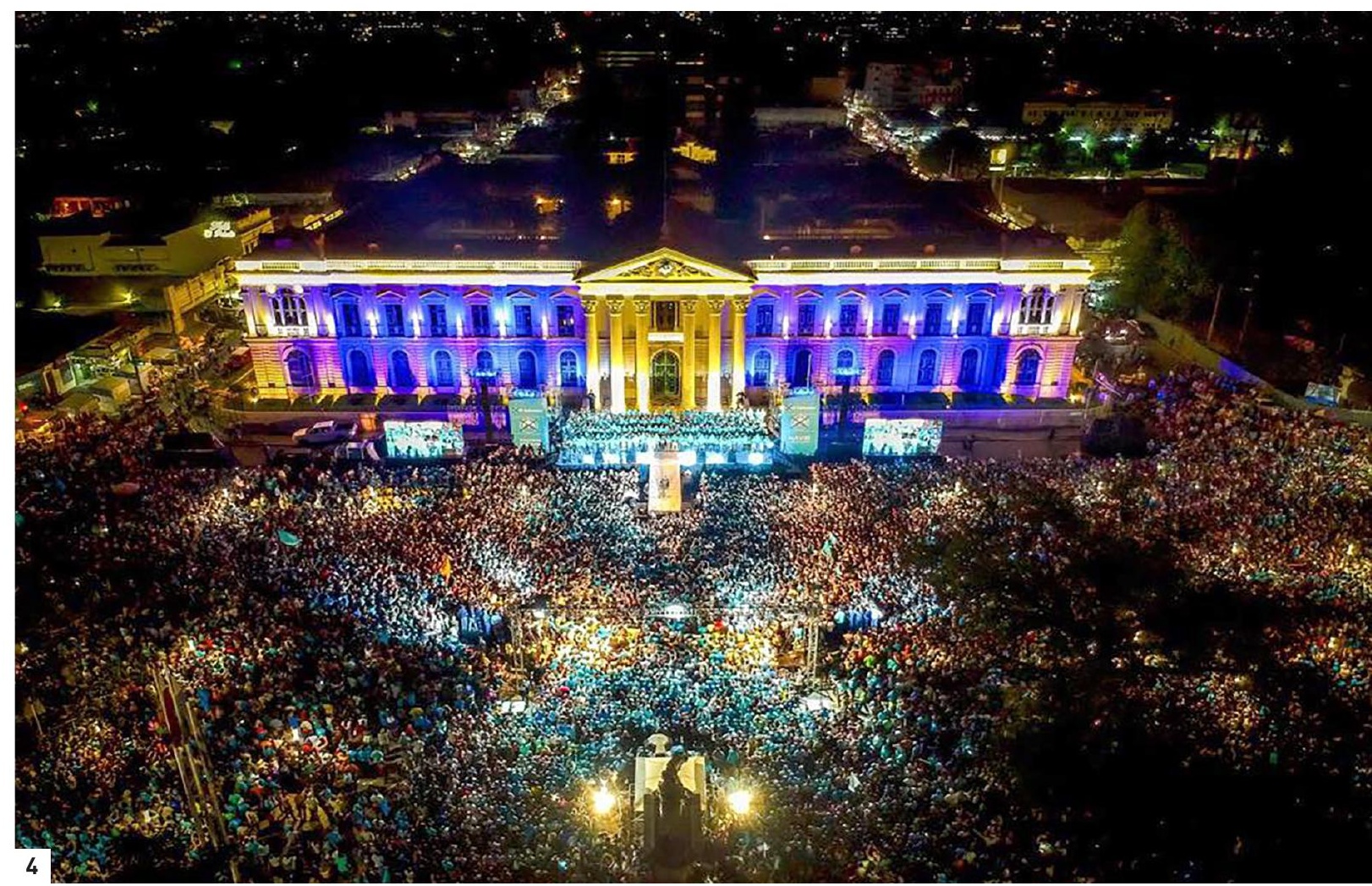

Imagen 4: Nuestro cierre, en el Centro Histórico de San Salvador. (Bukele, 26 de enero de 2019) Fuente: Facebook 
Finalmente, cada uno de los personajes que hablan sobre sus vidas y sus relaciones con Nuevas Ideas forman un acto de tipo testimonial sobre la decisión política suscrita. La verdad en el dispositivo de la propaganda se produce discursivamente en lo audiovisual, pero también se encuentra anclada a la historia de los cuerpos de los sujetos que la afirman: cuerpos que testimonian la guerra civil (María Chichilco), la discriminación y la violencia social (Verso) y la pobreza y la búsqueda de superación (Efraín). Es por esto que sus emociones no son excluidas sino destacadas como signos de la confesión.

\subsubsection{La gestión de probabilidades electorales}

En el dispositivo de la propaganda, las opiniones e intenciones de voto de las personas son inteligibilizadas en series numéricas para verificar la simpatía y apoyo del movimiento Nuevas Ideas. En un movimiento de retorno, las piezas audiovisuales verificaban las predicciones estadísticas y el apoyo al movimiento, en una presentificación de la y el votante con características específicas y unificadoras, relacionadas además a las que se consideran sus necesidades y aspiraciones. De cierta forma, lo que se indica es que la división entre escépticos/as y creyentes no pasa principalmente por un filtro de clase o lugar de residencia, sino de opiniones sobre la historia, el cambio y la renovación. El anuncio del fin del sujeto partidario tradicional pasa por la horizontalidad y flexibilidad de las definiciones con las que hablamos a las y los votantes.

Una de las funciones formalizadas de la propaganda es gestionar la inscripción voluntaria de las y los simpatizantes de Nuevas Ideas en la plataforma "Voluntarios por El Salvador", con la promesa de convertirse en la organización popular más grande en la historia nacional. La práctica permitía, en primer lugar, sopesar los posibles votos, describir a la población votante en secuencias numéricas, así como verificar las predicciones estadísticas de empresas encuestadoras nacionales y extranjeras.

\subsubsection{La modernización de la cotidianidad}

Nuevas Ideas se autodenomina un movimiento social y no un partido político. Esta afirmación puede tener sentido cuando lo consideramos una especie de antipartido, que no ha planteado todavía las condiciones de articular nuevas coordenadas sociales para el país, que signifiquen menos una forma aditiva en función del voto. A pesar de considerarse una crítica a las prácticas de corrupción y las malas decisiones de los otros partidos en competencia, no cuestiona de manera contundente el sistema económico o político, pues termina por confirmar o mejorar lo que ya existe. Podría decirse, en palabras de Rancière (2010), que es funcional a la policía del orden establecido y no plantea un verdadero ejercicio político.

Tal comprensión de la política nos hace ver la necesidad de resignificación (no casual) de las acciones de organización y movilización popular que pulularon en campaña electoral. Con el dispositivo propagandístico se esperaba: categorizar como política un intento policial de constatar la modernización y celebrar como destino nuestro ingreso al progreso mundial -asociado a la testificación de servicios y obras realizadas durante la administración de Nayib Bukele-; la verificación del disfrute de los espacios públicos construidos; la posibilidad de imaginar grandes obras e infraestructura; la demostración de reconocimiento y vinculación a entidades financieras y organismos internacionales. En este contexto, las significaciones sociales sobre la modernidad y el progreso son esos lugares comunes de las funciones formalizadas de la campaña, ideales para actualizar las relaciones de poder en las formas-sujetos y las formas-objetos que encontramos conformados por este dispositivo multilineal al que llamamos propaganda.

Al estudiar la propaganda como tecnología, Tello (2017), en concordancia con Bernays (2008), sostiene que los propagandistas elaboran un saber específico sobre cómo gestionar la opinión pública, acoplándose al régimen de veridicción del discurso económico. Estas reflexiones son retomadas del análisis de Foucault (2006), sobre cómo la sociedad representa el principio en cuyo nombre el gobierno tiende a limitarse, en cuanto obliga al gobierno a preguntarse si no gobierna demasiado. Asimismo, es el blanco de intervención gubernamental permanente, no para restringir las libertades otorgadas, sino para producir, multiplicar y garantizar las liber- 
figurarse dentro de la ficción de la campaña. La propaganda les daría un orden, un sentido y una administración. Segundo, la visibilidad política no se encuentra separada del pensamiento político. Cuando las personas observan el paisaje de escenas políticas también las están pensando y estas se relacionan con sus historias de vida, cuerpos y territorios. Tercero, no se considera a los públicos como una masa manipulable. Sus relaciones están cargadas de sentido y atraviesan procesos de racionalización consistentes a las lógicas de velocidad, orden, consumo global y transparencia, en tanto producción masiva e individualizante de información. Las personas son productoras y consumidoras de imágenes y discursos en búsqueda activa de medios de verificación de sus opiniones, también. Finalmente, no se discute la legalidad o factibilidad de las propuestas, sino las maneras de articular discursos de verdad y prácticas de verificación.

Estas implicancias resisten a otros procesos políticos, en tanto productores de escenas políticas contemporáneas. La investigación espera proporcionar coordenadas para pensar la manera en que constituimos -y somos constituidos- por imaginarios a los que acudimos en nuestra cotidianidad, así como las formas en que pensamos los espacios de producción de sentido de la comunicación. Las acciones y conocimientos que confluyen en la trama de una campaña presidencial son una muestra de lógicas colectivas e individuales complejas, que se relacionan con condiciones históricas, económicas y políticas, en un juego cambiante y multinivel.

\section{Referencias}

Agamben, G. (2011). ¿Qué es un dispositivo? Sociológica, 26 (73), 249-264.

Bernays, E. (2008). Propaganda. España: Melusina.

Bukele, N. (30 de enero de 2019). El camino que recorrimos. [Video]. https://www.youtube. com/watch?v=F-VuoHqr9k4

Bukele, N. (3 de octubre de 2018). Inicio de campaña. [Video]. https://www.youtube.com/ watch?v=0rdh2021 qhk

Bukele, N. (20 de enero de 2019). Verso. [Video]. https://www.facebook.com/ watch/?v=2221923991160962

Bukele, N. (26 de noviembre de 2018). El siguiente paso de nuestro movimiento. [Video]. https://www.facebook.com/watch/live/?v=354356818656840\&ref=watch_permalink

Bukele, N. (13 de noviembre de 2018). Sección sobre las maras en EuropaPress. [Video]. https://www.facebook.com/watch/?v=178455249767054

Bukele, N. (2 de noviembre de 2018). Conversatorio en la UCA [Video]. https://www.facebook. $\mathrm{com} /$ watch/?v=300230530818077

Bukele, N. (16 de noviembre de 2018). Nayib en la UES. [Video]. https://www.facebook.com/ watch/?v=497243297447201

Bukele, N. (29 de diciembre de 2018). Inscripción de los defensores de los votos. [Video]. https://www.facebook.com/100044244378596/videos/931132653758272

Carlini, A. (2 de julio de 2018). Las redes sociales como factor de desestabilización. Instituto Español de Estudios Estratégicos. http://www.ieee.es/Galerias/fichero/docs_opinion/2018/DIEEE079-2018_RRSS_FactorDesestabilizacion_ACarlini.pdf I

Castoriadis, C. (1987). The Imaginary Institution of Society. Cambridge: Polity Press. 
Castoriadis, C. (2013). La institución imaginaria de la sociedad (traducción de Antonio Vicens y Marco-Aurelio Galmarini). México: Fábula Tusquets Editores.

Cortés, C. \& Isaza, L. (2017). Noticias falsas en Internet: la estrategia para combatir la desinformación. Salamanca: Universidad de Salamanca. https://universoabierto.org/2019/04/13/noticias-falsas-en-internet-la-estrategia-para-combatir-ladesinformacion/

Deleuze, G. (1995). ¿Qué es un dispositivo? Michel Foucault, Filósofo. Barcelona: Gedisa

Deleuze, G. (1999). Post-scriptum sobre las sociedades de control. Conversaciones 1972-1990. España: Pre-Textos.

Deleuze, G. (2013). El saber. Curso sobre Foucault. Buenos Aires: Cactus

Deleuze, G. (2014). El poder: curso sobre Foucault II. Ciudad Autónoma de Buenos Aires: Cactus.

Doob, L. (1950). Goebbels y sus principios propagandísticos. The Public Opinion Quarterly, 14 (3), 419-442.

Domenach, J. (1968). La propaganda política. Buenos Aires: Editorial Universitaria de Buenos Aires.

Eire, A. \& Guervós, J. (2000). Retórica y Comunicación Política. Madrid: Ediciones Cátedra.

Ellul, J. (1973). Propaganda. The Formation of Men's Attitudes. New York: Vintage Books.

Freidenberg, F. (2012). El populismo en Latinoamérica: teoría, historia y valores. Salamanca: Universidad de Salamanca.

Foucault, M. (1991). Saber y verdad. Madrid: Endymión.

Foucault, M. (2006). Seguridad, territorio, población. Cursos del Colegio de Francia 1977-1978. Buenos Aires: Fondo de Cultura Económica.

Foucault, M. (2007). Historia de la sexualidad 1. La voluntad de saber. Buenos Aires: Siglo XXI Editores.

Foucault, M. (2010). Nacimiento de la biopolítica. Cursos del Colegio de Francia 1978-1979. Buenos Aires: Fondo de Cultura Económica.

Foucault, M. (2012). Vigilar y castigar: nacimiento de la prisión. Buenos Aires: Siglo XXI.

Foucault, M. (1993). Historia de la locura en la época clásica. Bogotá: Fondo de Cultura Económica.

Glaser, B. \& Strauss, A. (1967). (Teoría Fundamentada). En Hernández, R., Fernández, E. \& Baptista, P. (Eds.), Metodología de la investigación. México: McGraw-Hill.

Hernández, S. Fernández Collado, E. \& Baptista L. P. (1991). Metodología de la Investigación. México: McGraw-Hill.

Jäger, S. (2001). (Discurso y conocimiento: aspectos teóricos y metodológicos de la crítica del discurso y de análisis de dispositivos). En Wodak, R. \& Meyer, M. (Eds.). Métodos de análisis críticos del discurso. Barcelona: Gedisa.

Lipovetsky, G, \& Charles, S. (2004). Los tiempos hipermodernos. Barcelona: Anagrama.

Marroquín, M. \& Girón, G. (2019). Tuit por tuit y voto por voto. La construcción de perfiles políticos en Twitter en las campañas electorales de \#ElSalvador y \#Guatemala 2019. Recuperado de: https://sv.boell.org/es/2019/12/16/tuit-por-tuit-y-votopor-voto-la-construccion-de-perfiles-politicos-en-twitter-en-las 
Pizarroso, A. (1999). La historia de la propaganda: una aproximación metodológica. Historia y Comunicación Social, 4, 145-171.

Pratkanis, A. \& Aronson, E. (1994). La era de la propaganda. Uso y abuso de la persuasión. España: Paidós.

Rancière, J. (2010). El espectador emancipado. Buenos Aires: Manantial.

Rosa, H. (2013). Social Acceleration. A new theory of modernity. New York: Columbia University Press.

Scolari, C. (2012). Narrativas transmedia. Cuando todos los medios cuentan. España: Deusto.

Sierra, F. (s.f.) La propaganda. Recuperado de: http://www.franciscosierracaballero.com/ la-propaganda/

Sloterdijk, P (2002). El desprecio de las masas. Un ensayo de las luchas culturales en la época moderna. Madrid: Pre Textos.

Taylor, C. (2004). Modern Social Imaginaries. Durham: Duke University Press.

Taylor, P. M. (2003). Munitions of the Mind. A history of propaganda from the ancient world to the present era. Manchester: Manchester University Press.

Tello, A. M. (2017). Tecnologías de la propaganda: contribuciones para una genealogía sobre el gobierno del público. Revista Faro, Universidad de Playa Ancha, 2 (26). https:// www.revistafaro.cl/index.php/Faro/article/view/533/492

Toret, J. (coord.) (2013). Tecnopolítica: la potencia de las multitudes conectadas. El sistema red $15 \mathrm{M}$, un nuevo paradigma de la política distribuida. Recuperado de: https://tecnopolitica.net/sites/default/files/1878-5799-3-PB\%20(2).pdf

\section{- Sobre la autora:}

Tatiana Orantes es Magíster en Comunicación Política por la Universidad de Chile. Licenciada en Comunicación Social por la Universidad Centroamericana José Simeón Cañas. Se ha formado también en políticas públicas con perspectiva de género, gestión de proyectos, transparencia e integración regional.

\section{- ¿Cómo citar?}

Orantes, T. (2021). El dispositivo de la propaganda en las redes sociales de la campaña presidencial de El Salvador (2018-2019). Comunicación y Medios, (43), 60-77. https://doi. org/10.5354/0719-1529.2021.58774 